\title{
Administration of Testosterone and its Rationale in the Treatment of Erectile Dysfunction
}

\author{
${ }^{*}$ CATM Mowladad ${ }^{1}$, HM Rafiqul $^{2}$, A Bakhtiar $^{3}, \mathrm{KM}_{\text {Rahman }}^{4}$, R Shofiqur ${ }^{5}$ \\ ${ }^{*}$ Prof. Chowdhury ATM Mowladad, Department of Urology, BIRDEM General Hospital, Dhaka \\ ${ }^{2}$ Dr. Hassan Md Rafiqul, Department of Urology, BIRDEM General Hospital, Dhaka, Bangladesh \\ ${ }^{3}$ Dr. Ahmed Bakhtiar, Department of Urology, BIRDEM General Hospital, Dhaka, Bangladesh \\ ${ }^{4}$ Dr. Khan Mohiur Rahman, Department of Urology, BIRDEM General Hospital, Dhaka, Bangladesh \\ ${ }^{5}$ Dr. Rahman Shofiqur, Department of Urology, BIRDEM General Hospital, Dhaka, Bangladesh
}

*Corresponding Author

Date of submission: 20.08.2016 Date of acceptance: 17.11.2016

\begin{abstract}
Background: Despite increasing use of testosterone in the management erectile dysfunction, debate remains regarding the selection of candidate for the hormonal treatment. The aim of this study is to find out the role of testosterone in erectile dysfunction (ED), the incidence of testosterone deficiency in the patient of ED and therapeutic response of testosterone in ED in common practice.

Material \& Methods: This cross-sectional study had conducted among the patients with age above 30 years, complaining of erectile dysfunction treated with testosterone by self-medication or clinical practitioners. Total 103 cases interviewed, who attended the private chamber of Urologists and the Urology OPD, BIRDEM General Hospital between periods of April 2014 to September 2015.

Result: Of 103 cases, testosterone level was normal in $78.6 \%$ cases. All were treated with testosterone. Among the participants $47.57 \%$ were between 30-40 years and $9.09 \%$ were of the age between $60-70$ years. Twenty-two patients having testosterone deficit were treated with testosterone supplement and marked improvement was observed $(88.1 \%)$. In this study 49 patients having normal testosterone level received testosterone along with sildenafil or tadalafil, of these 47 cases $(95 \%)$ had moderate to marked improvement. On the other hand 32 patients having normal testosterone level received testosterone monotherapy but there was no improvement in $87.5 \%$ cases.

Conclusion: The result of the study suggests that testosterone replacement therapy is beneficial in patient of ED due to hypogonadism. However, testosterone monotherapy in erectile dysfunction with normal testosterone level should be considered injudicious.
\end{abstract}

Key Words: erectile dysfunction, testosterone, sildenafil, tadalafil

\section{Introduction}

A study reported that there were about 152 million men with complaints of erectile problems in the whole world in 1995, and this number would rise to approximately 322 million in 20251. Particularly in the early 1980s, significant advances in the knowledge and comprehension of erectile physiology were made; new knowledge regarding the importance of organic causes has led to the change of prevailing perception that most EDs have a psychogenic origin ${ }^{2}$. Since ED is a disease of the aging, it is quite difficult to determine an isolated single factor in its etiology, because in aged individuals, systemic diseases including diabetes mellitus (DM), renal insufficiency and cardiovascular diseases, hormonal changes, chronic use of medications, surgical interventions and aging of tissues become isolated or cumulative underlying factors. Recent studies have shown that testosterone (T) deficiency can lead to diseases with potential morbidity such as metabolic syndrome, osteoporosis, and coronary artery disease. Although the role of hormones in ED has not been fully clarified, some indicative data have been obtained. 
Hormones that may be possibly related to ED are androgens (testosterone $=\mathrm{T}$, dihydrotestosterone $=$ DHT, androstenedione, dehydroepiandrosterone $=$ DHEA and dehydroepiandrosterone-sulphate = DHEA SO4), estrogens (in particularly, estradiol = E2), insulin (cause of DM and consequently, an indirect cause of ED), thyroid hormones, prolactin (PRL), melatonin, leptin and growth hormone (GH). It has been demonstrated that hormones are responsible for about $5 \%$ of ED cases with organic causes. In particular, a serum $\mathrm{T}$ level of $<300$ $\mathrm{ng} / \mathrm{dLis}$ found in $10-20 \%$ of ED patients ${ }^{3,4}$.

The introduction of phosphodiesterase ${ }^{5}$ (PDE5) inhibitors for treatment of ED was a major step forward due to their efficacy, safety and simple use. However, approximately one third of patients do not respond to PDE5 inhibitors. ${ }^{5}$ Moreover, patients taking nitrates cannot take PDE5 inhibitors. ${ }^{6-8}$ In addition, theseagents have no effect on libido, ${ }^{5-8}$ an essential componentof sexual function. Although the role of testosterone inimproving libido is well known, its exact function inthe pathophysiology of erection is still ill defined. However, testosterone is widely prescribed by general practitioners for the treatment of ED.

Our aim was to see the effect of testosterone on ED and its judicious use among the patients of erectile dysfunction who were treated with testosterone by self-medication or practitioners.

\section{Materialand Methods}

This cross-sectional study had conducted among the patients with age above 30 years, complaining of erectile dysfunction treated with testosterone by selfmedication or clinical practitioners. Total 103 cases interviewed, who attended the private chamber of Urologists and the Urology OPD, BIRDEM General Hospital between periods of April 2014 to September 2015. All cases were invited to answer voluntarily the IIEF-5 questionnaire containing 15 questions. It discusses the following parameters of sexual function: erectile function, orgasmic function, sexual desire, satisfaction with relations and overall satisfaction. The relevant investigations done previously were also reviewed.

Data were collected, processed, analyzed, and evaluated statistically using Analysis of Variance (ANOVA) and the Student's t-test. Chi-square test
CATM Mowladad, HM Rafiqul, A Bakhtiar et al

was used for proportional data. An alpha of 5\% $(\mathrm{P}<0.05)$ was considered for purposes of statistical significance.

\section{Result}

A total 103 patients of ED were included in this study based on inclusion \& exclusion criteria. Age distribution of the study population is plotted in table 1 which shows that majority of the study population was in 30-40 years of age group $(61.5 \%$ \& $50 \%$ in no deficiency \& testosterone deficiency groups respectively).

Age distribution Normal testosterone \% Testosterone deficiency $\%$

Table I: Age distribution of the study population

\begin{tabular}{ccccc}
\hline $\begin{array}{c}\text { Age } \\
\text { distribution }\end{array}$ & $\begin{array}{c}\text { Normal } \\
\text { testosterone }\end{array}$ & $\% \begin{array}{c}\text { Testosterone } \\
\text { deficiency }\end{array}$ & $\%$ \\
\hline $\mathbf{3 0 - 4 0}$ & 49 & 47.57 & 11 & 10.68 \\
$\mathbf{4 0 - 5 0}$ & 17 & 16.50 & 6 & 5.83 \\
$\mathbf{5 0 - 6 0}$ & 8 & 7.77 & 3 & 2.91 \\
$\mathbf{6 0 - 7 0}$ & 7 & 6.80 & 2 & 1.94 \\
$\mathbf{N}$ & $\mathbf{8 1}$ & $\mathbf{7 8 . 6 4}$ & $\mathbf{2 2}$ & $\mathbf{2 1 . 3 6}$ \\
Mean \pm SD (Years) & $36 \pm 1.9$ & & $38 \pm 2.3$ & \\
\hline
\end{tabular}

Among the total number of 103 study population, testosterone was given in 103 patients $(59.5 \%)$. $78.6 \%$ (81) patients out of 103 patients of testosterone therapy had normal testosterone level where as $22(21.4 \%)$ patients had testosterone deficit. Table 3 reflects that patients with low testosterone responded quite well $(88.1 \%)$ to testosterone therapy with improvement of libido and erectile performance. On the contrary, patients with normal testosterone level 32 patients $(39.5 \%)$ who treated with testosterone therapy alone does not show satisfactory change in erectile performance and the patient with normal testosterone group who are treated with sildenafil or tadalafil along with testosterone (49 patients $60.5 \%$ ), shows satisfactory improvement in erectile function. P-value was quite significant here $(<0.01)$ (Table 2). Analysis of this finding can be inferred, as patients of erectile dysfunction having normal testosterone level do not show further improvement in testosterone treatment. 
Administration of Testosterone and its Rationale in the Treatment

Table II: Modalities of treatment and their response

\begin{tabular}{|c|c|c|c|c|c|}
\hline \multirow[b]{2}{*}{ Category } & \multirow[b]{2}{*}{$\begin{array}{l}\text { Treatment } \\
\text { options }\end{array}$} & \multicolumn{3}{|c|}{ Treatment response for ED } & \multirow[b]{2}{*}{ Pvalue } \\
\hline & & $\begin{array}{l}\text { Marked } \\
\text { provement }\end{array}$ & $\begin{array}{l}\text { Moderate } \\
\text { improvement }\end{array}$ & $\begin{array}{c}\text { Poor } 1 \\
\text { improvement }\end{array}$ & \\
\hline \multirow{2}{*}{$\begin{array}{l}\text { Testosterone } \\
\text { Deficiency } \\
(n=22, \\
21.4 \%) \\
\text { / T }\end{array}$} & $\begin{array}{l}\text { Testosterone } \\
\mathbf{2 2}(\mathbf{1 0 0 \% )}\end{array}$ & $\begin{array}{c}20 \\
(88.1 \%)\end{array}$ & 00 & $\begin{array}{c}02 \\
(11.09 \%)\end{array}$ & \multirow[b]{2}{*}{$<0.01$} \\
\hline & $\begin{array}{c}\text { Testosterone }+ \\
\text { Sildenafil } \\
\text { adalafil } 0(\mathbf{0 \% )}\end{array}$ & 00 & 00 & 00 & \\
\hline \multirow{2}{*}{$\begin{array}{c}\text { Normal } \\
\text { Testosterone } \\
(\boldsymbol{n}=\mathbf{8 1}, \\
\mathbf{7 8 . 6 \% )}\end{array}$} & $\begin{array}{l}\text { Testosterone } \\
\mathbf{3 2}(\mathbf{3 9 . 5 \% )}\end{array}$ & 00 & $04(12.5 \%)$ & $\begin{array}{c}28 \\
(87.5 \%)\end{array}$ & \multirow[b]{2}{*}{$<0.01$} \\
\hline & $\begin{array}{l}\text { Testosterone }+ \\
\text { Sildenafil } \\
\text { / Tadalafil } \\
\mathbf{4 9 ( 6 0 . 5 \% )}\end{array}$ & 00 & $47(95 \%)$ & $02(5 \%)$ & \\
\hline
\end{tabular}

\section{Discussion}

This study was conducted to see the rationality of use of testosterone among the patient complaining of erectile dysfunction. Experimental animal studies have demonstrated the relationship between testosterone and $\mathrm{ED}^{9}$. In patients for whom testosterone replacement therapy (TRT) has been planned, the complaints and symptoms related to erectile dysfunction can be nonspecific. Although there is no definite evaluation method for the diagnosis, in the first examination, questionnaires such as the IIEF (international index of erectile dysfunction), ADAM (androgen decline in the aging male) and AMS (aging male survey) should be used. Investigation of the serum Testosterone level is recommended when there are high symptom scores accompanied by ED, lack of libido, loss of muscle mass, metabolic syndrome and diabetes mellitus type $2^{10}$. The first choice of therapy in ED is PDE-5 inhibitors, but this therapy results in no response in $30-50 \%$ of the patients. When TRT is added to the therapy of non-responders, the outcome is positive ${ }^{11}$.

The data in this study do not refiect the ED prevalence in this region. The participants, however, sought medical care for ED. Moreover, the population studied did not consist only of the aged, and also did not include subjects who were being followed up for some andrological problem. The interest in researching the erectile function was only revealed at the time of the interview, and the patients were not previously aware of the objective of the study. The questionnaire used in this study as a diagnostic tool is currently the only one recommended by the National Institute of Health (1993) to evaluate penile erectile function ${ }^{12}$. Furthermore, it allows a grading of ED severity. The direct relationship between ED and aging is well established, by data from several studies ${ }^{12,13}$. In our study most of the patient receiving treatment for ED is young. An interesting socio-cultural influence is well exhibited in the result i.e decline of incidence of taking treatment in advanced age group seems due to acceptance of reduced sexual activity in older age in our country.

In our study, testosterone deficit was noted in 22 cases and they were treated with testosterone replacement therapy showed marked improvement $(88.1 \%)$ of erectile performance with improvement of libido.

Various studies show the same result. In a study by MoraleyA et al showed testosterone replacement therapy was associated with significant efficacy in the treatment of hypogonadism and ED, with improvement in sexual attitudes and performance in $61 \%$ of patients ${ }^{14}$. A meta-analysis indicated $57 \%$ efficacy for testosterone replacement therapy in patients with ED and hypogonadism, ranging from $64 \%$ for primary hypogonadism to $44 \%$ for secondary hypogonadism ${ }^{15}$. In another study, testosterone monotherapy improved erectile function and penile vascular abnormalities in $36 \%$ and $42 \%$ of cases respectively ${ }^{16}$. In general, testosterone monotherapy for the treatment of ED is efficacious in men when the sole cause of ED is hypogonadism. But it is often not efficacious in other pathophysiologies such as vascular disease and neuropathy.

In this study, 49 patient who had normal testosterone level but received testosterone along with sildenafil or tadalafil. Of these 47 cases (95\%) had moderate improvement of erectile performance. Other studies have confirmed the beneficial effects of combination therapy. The combination of testosterone and sildenafil were shown to improve erectile function in eugonadal men ${ }^{17}$. This improvement was superior to sildenafil or testosterone alone ${ }^{17}$. Chaterjee et al showed administration of intramuscular testosterone and sildenafil was efficacious in eugonadal $\operatorname{man}^{18}$. Oral testosterone was reported to reverse ED 
associated with type 2 diabetes in patients failing on sildenafil therapy alone ${ }^{18}$. In a recent study, a total of 49 hypogonadal men with ED received T-gel for 6 months. Sildenafil was added at 3 months to those with no efficacy of T-gel alone. A total of 31 patients reported significant improvement in the sexual desire and erectile function with testosterone alone. In spite of normalization of total and bioavailable testosterone values, and significant improvement of sexual desire, the erectile function of 17 men did not improve ${ }^{19}$. These men received combined T-gel and sildenafil, after which all reported improvement in erectile function. A prospective study included hypogonadal men failing to respond to sildenafil or partially responding to sildenafil. Men receiving both sildenafil plus testosterone replacement therapy showed significant improvement in erectile function ${ }^{20}$.

However, the patient with normal testosterone treated with only testosterone supplement for erectile dysfunction does not show satisfactory change in erectile performance $(12.5 \%)$. Other study support our study. At present, there is no basis for largescale testosterone replacement therapy in older men, unless they have symptomatic androgen deficiency 21,22 . Testosterone levels needed for normal sexual function vary among individuals. Some men may have normal sexual function even if their testosterone levels fall into the ageadjusted lower normal range ${ }^{22}$. However, in patients with sexual dysfunction, testosterone testing is advised to screen for hypogonadism ${ }^{23}$, and testosterone replacement therapy is appropriate when clinical symptoms and biochemical evidence of hypogonadism exist ${ }^{21,23}$. Hypogonadal men with specific sexual dysfunctions such as ED, diminished libido, or both, are candidates for testosterone replacement therapy ${ }^{21,23}$. Testosterone monotherapy may correct sexual dysfunction caused by hypogonadism, but absence of an adequate response may require further evaluation to exclude associated comorbidities, such as those causing vasculogenic or neurogenic $\mathrm{ED}^{23}$.

\section{Conclusion}

This study corroborates the data from the literature as regard as the relationship between ED and testosterone. Testosterone replacement therapy is clearly indicated in hypogonadism patients and is beneficial in patient with ED and hypogonadism. However, testosterone monotherapy for erectile dysfunction without identified hypogonadismis being prescribed by the practitioners are ineffective and therefore can be opined as injudicious. Adult ED cases can be effectively treated with PDE5 inhibitors or other vasodilators in most of the cases.

Conflict of interest: Authors declared that they have no conflict of interest.

\section{References}

1. Ayta IA, McKinlay JB, Krane RJ. The likely worldwide increase in erectile dysfunction between 1995 and 2025 and some possible policy consequences. BJU Int.1999; 84(1): 50-6.

2. Bivalacqua TJ, Usta MF, Champion HC, Adams D, Namara DB, Abdel-Mageed AB, et al. Gene transfer of endothelial nitric oxide synthase partially restores nitric oxide synthesis and erectile function in streptozotocin diabetic rats. J Urol.2003; 169(5): 1911-7.

3. Roumeguere T. Rationale for androgens and erectile dysfunction in 2006. Eur Urol.2006; 50(5): 898-900.

4. Buvat J, BouJaoude G. Significance of hypogonadism in erectile dysfunction. World J Urol.2006; 24(6): 657-67.

5. Goldstein I, Lue TF, Padma-Nathan H, Rosen RC, Steers WD, Wicker PA, for the Sildenafil Study Group. Oral sildenafil in the treatment of erectile dysfunction. N Engl J Med. 1998; 338: 1397-1404.

6. Viagra (sildenafil citrate). Prescribing information 2002.

7. Levitra (vardenafil HCL). Prescribing information 2003.

8. Cialis (tadalafil). Prescribing information 2003

9. Traish AM, Park K, Dhir V, Kim NN, Moreland RB, Goldstein I. Effects of castration and androgen replacement on erectile function in a rabbit model. Endocrinology.1999; 140(4): 1861-8.

10. Channer K, Dumas C. Prospective evaluation of the effects of testosterone therapy in hypogonadal men with type 2 diabetes or metabolic syndrome: demographic analysis of TIMES2 study. Diabetes Vasc Dis Res.2007; 4: 164-8.

11. Palumbo F, Bettocchi C, Selvaggi FP, Pryor JP, Ralph DJ. Sildenafil: efficacy and safety in daily clinical experience. Eur Urol. 2001; 40(2): 176-80.

12. NIH Consensus Development Panel on Impotence. JAMA1993; 270: 83- 90 
13. Feldman HA, Goldstein I, Hatzichristou DG, KraneRJ,McKinlay JB. Impotence and its medical and psycho-socialcorrelates: results of the Massachusets Male Aging Study. J Urol 1994; 151: 54- 61.

14. Morley JE. Impotence. Am J Med 1986; 80: 897-905.

15. Morales A, Johnston B, Heaton JPW, Lundie M. Testosteronesupplementation for hypogonadal impotence: assessment ofbiochemical measures and therapeutic outcomes. J Urol 1997; 157: 849-54.

16. Jain P, Rademaker AW, McVary KT. Testosterone supplementationfor erectile dysfunction: results of a metaanalysis. JUrol 2000; 164: 371-5.

17. Schiavi RC, White D, Mandeli J, Levine AC. Effect of testosteroneadministration on sexual behavior and mood in menwith erectile dysfunction. Arch Sex Behav 1997; 26: $231-41.30$

18. Chatterjee R, Wood S, McGarrigle HH, Lees WR, Ralph DJ,Neild GH. A novel therapy with testosterone and sildenafil forerectile dysfunction in patients on renal dialysis or after renaltransplantation. J FamPlannReprod Health Care 2004; 30: 88-90.
19. Greenstein A, Mabjeesh NJ, Sofer M, Kaver I, MatzkinH,Chen J. Does sildenafil combined with testosterone gel improveerectile dysfunction in hypogonadal men in whom testosterone supplement therapy alone failed? J Urol 2005; 173: 530-2.

20. Shamloul R, Ghanem H, Fahmy I et al. Testosterone therapycan enhance erectile function response to sildenafil in patientswith PADAM: a pilot study. J Sex Med 2005; 2: 559-64.

21. Morales A, Buvat J, Gooren LJ et al. Endocrine aspects of sexualdysfunction in men. In: Lue TF, Basson R, Rosen R, GiulianoF, Khoury S, Montorsi F, eds. Sexual Medicine: SexualDysfunctions in Men and Women. 2nd International Consultationon Erectile and Sexual Dysfunction. Paris, France: HealthPublications, 2004: 347-82.

22. Handelsman DJ, Zajac JD. Androgen deficiency and replacementtherapy in men. Med J Aust 2004; 180: 529-35.

23. AACE Male Sexual Dysfunction Task Force. American Associationof Clinical Endocrinologists medical guidelines for clinicalpractice for the evaluation and treatment of male sexualdysfunction: a couple's problem - 2003 update. Endocr Pract 2003; 9: 77-94. 